\title{
Applicability of empirical formulas and fractography for assessment of creep life and creep fracture modes of tempered martensitic $9 \% \mathrm{Cr}$ steel
}

\author{
V. Sklenička ${ }^{1,2 *}$, K. Kuchařová ${ }^{1}$, P. Král ${ }^{1,2}$, M. Kvapilová ${ }^{1,2}$, J. Dvořák ${ }^{1,2}$ \\ ${ }^{1}$ Institute of Physics of Materials, Academy of Sciences of the Czech Republic, Žižkova 22, 61662 Brno, Czech Republic \\ ${ }^{2}$ CEITEC IPM, Institute of Physics of Materials, Academy of Sciences of the Czech Republic, \\ Žižkova 22, 61662 Brno, Czech Republic
}

Received 12 January 2017, received in revised form 14 February 2017, accepted 15 February 2017

\begin{abstract}
In this study, the creep behaviour of P92 steel in as-received condition and after longterm isothermal ageing was investigated at 600 and $650{ }^{\circ} \mathrm{C}$ using uniaxial tension creep tests. The creep testing was carried out in the power-law creep region. The analyses of creep data indicate that creep behaviour of the steel under investigation obeys both Monkman-Grant and modified Monkman-Grant empirical formulas and provides high values of creep damage factor $\lambda$. The tertiary creep was examined in terms of the variations of the time to onset of tertiary creep $t_{\mathrm{ot}}$ with the time to fracture $t_{\mathrm{f}}$. To assess the effect of damage process on the loss of creep strength, most creep tests were followed by fractographic investigations. It was observed that the large Laves phase particles, which coarsened during creep exposure, served as preferred sites for creep cavity nucleation. The fractography of creep ruptured specimens revealed a dominant transgranular fracture mode by necking at the highest stresses, and a mixture of transgranular and intergranular fracture modes at medium and low-stress regions.

K e y w or d s: P92 steel, mechanical characterisation, creep, plasticity, fracture, electron microscopy
\end{abstract}

\section{Introduction}

Damage processes in creep are phenomena of major practical relevance, often limiting the lives of power plant components and structures designed to operate for long periods under stress at elevated and/or high temperatures. The steadily improved creep-resistant modified $9-12 \% \mathrm{Cr}$ ferritic steels have been used to construct new coal-fired ultra-supercritical (USC) power plants with higher efficiency [1-4]. However, the further development and safe using of advanced tempered martensitic 9-12\% Cr steels with improved longterm creep strength relies on a better understanding of the long-term microstructural and damage evolution, and its influence on the creep strength and life.

Advanced tungsten-modified $9 \% \mathrm{Cr}$ ferritic steel (ASTM Grade P92) is a promising material for the next generation of fossil and nuclear power plants [58]. The creep in modified P92 steel has been widely reported [5-15]. Its creep behaviour has been examined in terms of the variation of creep flow with time and strain, stress and temperature dependences of the minimum creep rate, the time to fracture and creep ductility. Furthermore, in recent years, extensive experimental studies and thermodynamic modelling of the microstructure and microstructural stability during high-temperature creep of P92 steel have been reported $[3,4]$. Research into the microstructural evolution during creep and its implications for damage behaviour in creep-resistant steels is needed for a fundamental understanding of the mechanisms of creep fracture processes. Unfortunately, there are only a few studies in the area of their creep fracture behaviour; most focus on Type IV cracking in 9-12\% Cr steel weldments [16, 17]. Accordingly, there is a clear demand for deeper knowledge and relevant creep data and their possible using in creep life assessment methods.

*Corresponding author: tel.: +420 532290 454; e-mail address: sklen@ipm.cz 
Recently, Sklenička et al. [15] presented an extensive study of creep behaviour and evolution of microstructure of P92 steel with the aim to identify acting creep deformation mechanisms and instability of microstructure. In this study, using the earlier published creep data [15] of uniaxial creep testing in tension, which have been considerably extended, the creep fracture characteristics of P92 steel will be analysed by linking them to the identified creep degradation mechanisms, in terms of empirical formulas for the fracture time assessment $[18,19]$, and by the creep damage tolerance factor $\lambda[20-26]$ as an important outcome of the continuum damage mechanics (CDM) approach. The data analysis will be followed by fractographic analyses, which will be used to identify the creep fracture mode(s) experimentally.

\section{Material and procedures}

\subsection{Material and processing}

The material of the commercial thick-wall pipe under investigation was $\mathrm{W}$-alloyed $9 \% \mathrm{Cr}$ P92 steel (ASME Grade 92) produced by Productos Tubulares, s.a.u., Spain [15]. The original dimensions of this pipe were OD $350 \mathrm{~mm} \times \mathrm{WT} 39 \mathrm{~mm}$. The chemical composition of the steel indicates no difference from ASTM $\mathrm{A} 213$ as follows (in wt.\%): $0.11 \mathrm{C}, 0.37 \mathrm{Si}, 0.48 \mathrm{Mn}$, $0.013 \mathrm{P}, 0.005 \mathrm{~S}, \quad 8.58 \mathrm{Cr}, 0.33 \mathrm{Mo}, 0.23 \mathrm{~V}, 0.06 \mathrm{Nb}$, $0.037 \mathrm{~N}$, and $1.62 \mathrm{~W}$. In the as-received state P92 steel was subjected to the heat treatment consisting of normalising at $1050^{\circ} \mathrm{C} / 60 \mathrm{~min} /$ air followed by tempering at $740^{\circ} \mathrm{C} / 140 \mathrm{~min} /$ air. In order to accelerate microstructural changes and thus to simulate the degradation of the microstructure under long-term service conditions, static isothermal ageing at $650{ }^{\circ} \mathrm{C}$ for $10,000 \mathrm{~h}$ was applied to selected creep specimens before creep exposures. The state after isothermal ageing will be denoted as the aged one.

\subsection{Creep testing and fractography}

Constant load creep tests in tension were carried out in argon using flat creep specimens having a gauge length of $50 \mathrm{~mm}$ and a cross-sectional area of $5 \mathrm{~mm} \times 3.2 \mathrm{~mm}$. Creep specimens were machined from the central parts of the wall thickness of the pipe. The creep testing was conducted at 600 and $650^{\circ} \mathrm{C}$ with the testing temperature maintained to within $\pm 0.5^{\circ} \mathrm{C}$ of the desired value. The initial applied tensile stresses ranged from 75 to $250 \mathrm{MPa}$. All tests were continued until the final fracture. The creep elongations were measured using a linear variable differential transducer (the strain was measured with a sensitivity of $5 \times 10^{-6}$ ), and they were continuously recorded digitally and then computer processed. The fractured creep testing specimens were prepared for fractographic examinations using light, transmission and scanning electron microscopy. Transmission electron microscopy (TEM) studies were carried out on carbon extraction replicas and thin foils using a Jeol $2100 \mathrm{~F}$ operating at $200 \mathrm{kV}$ equipped with X-Max 80 Oxford Instruments EDS detector for X-ray microanalysis. Creep damage on the longitudinal metallographic sections and creep fracture surfaces were investigated using a Tescan Lyra 3 scanning electron microscope.

\section{Empirical formulas}

The minimum creep rate $\dot{\varepsilon}_{\mathrm{m}}$ can be inversely linked to the fracture time $t_{\mathrm{f}}$ using the Monkman-Grant (MG) phenomenological equation [18]:

$$
\left(\dot{\varepsilon}_{\mathrm{m}}\right)^{\alpha} t_{\mathrm{f}}=C_{\mathrm{MG}}
$$

where $\alpha$ and $C_{\mathrm{MG}}$ are constants. The Monkman-Grant equation has been modified by Dobeš and Milička [19] for materials that generally exhibit larger tertiary creep strain and smaller secondary creep strain as $[19$, 27]:

$$
\left(\dot{\varepsilon}_{\mathrm{m}}\right)^{\alpha} t_{\mathrm{f}} / \varepsilon_{\mathrm{f}}=C_{\mathrm{MMG}},
$$

where $C_{\mathrm{MMG}}$ is the modified Monkman-Grant constant. Based on a continuum damage mechanics (CDM) approach, the creep damage tolerance factor $\lambda$ has been defined as the ratio of strain to fracture to Monkman-Grant ductility as [23]:

$$
\lambda=\varepsilon_{\mathrm{f}} / \dot{\varepsilon}_{\mathrm{m}} t_{\mathrm{f}}=1 / C_{\mathrm{MMG}} .
$$

The creep damage tolerance factor $\lambda$ has been used to assess the creep damage mode [23-26]. It is a significant parameter in assessing the susceptibility of the material to localised cracking at strain concentrations and has also been suggested as a better measure of creep ductility [21].

\section{Results}

\subsection{Summary of creep testing}

Constant load creep tests in tension were carried out at testing temperatures of 600 and $650^{\circ} \mathrm{C}$ on P92 steel in two different microstructural states: asreceived condition and after isothermal static ageing. The results of creep testing are summarised in Fig. 1. In Fig. 1a, the minimum creep rates $\dot{\varepsilon}_{\mathrm{m}}$ are plotted against applied stresses $\sigma$ for both states of the material. From Fig. 1a it can be seen that the minimum 

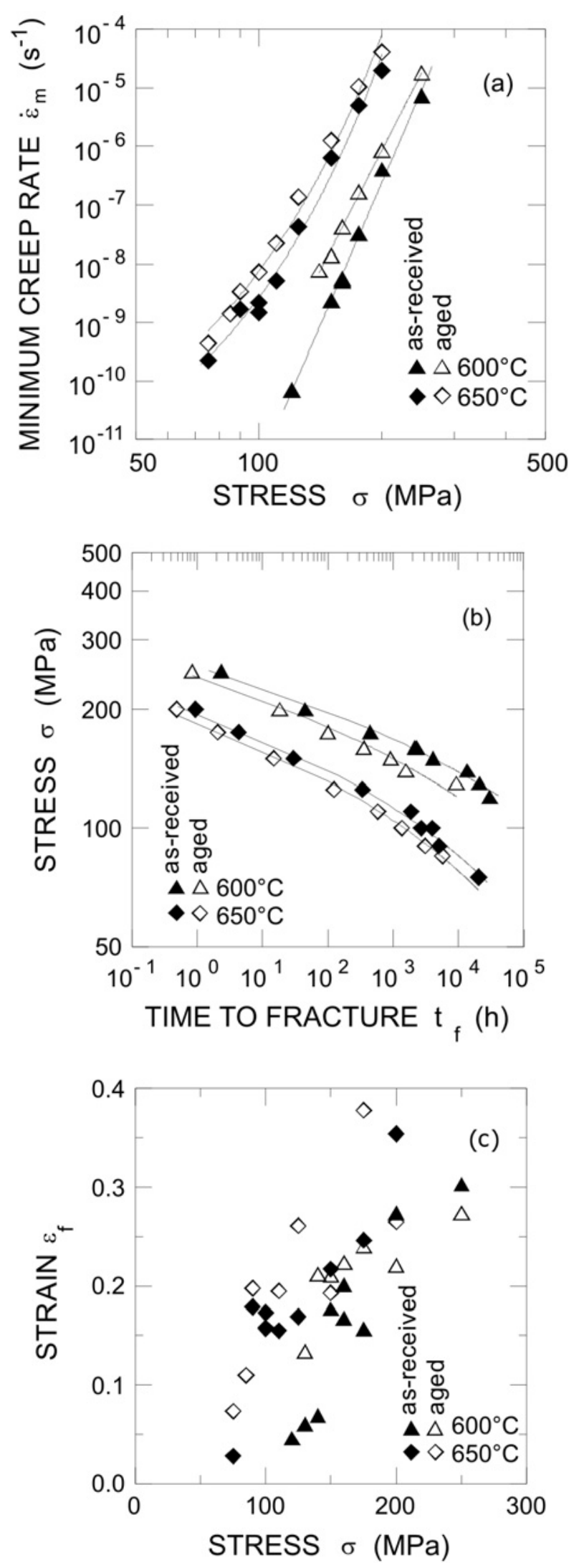

Fig. 1. Creep results for P92 steel showing: (a) minimum creep rate versus stress, (b) time to fracture versus stress, (c) strain to fracture versus stress.
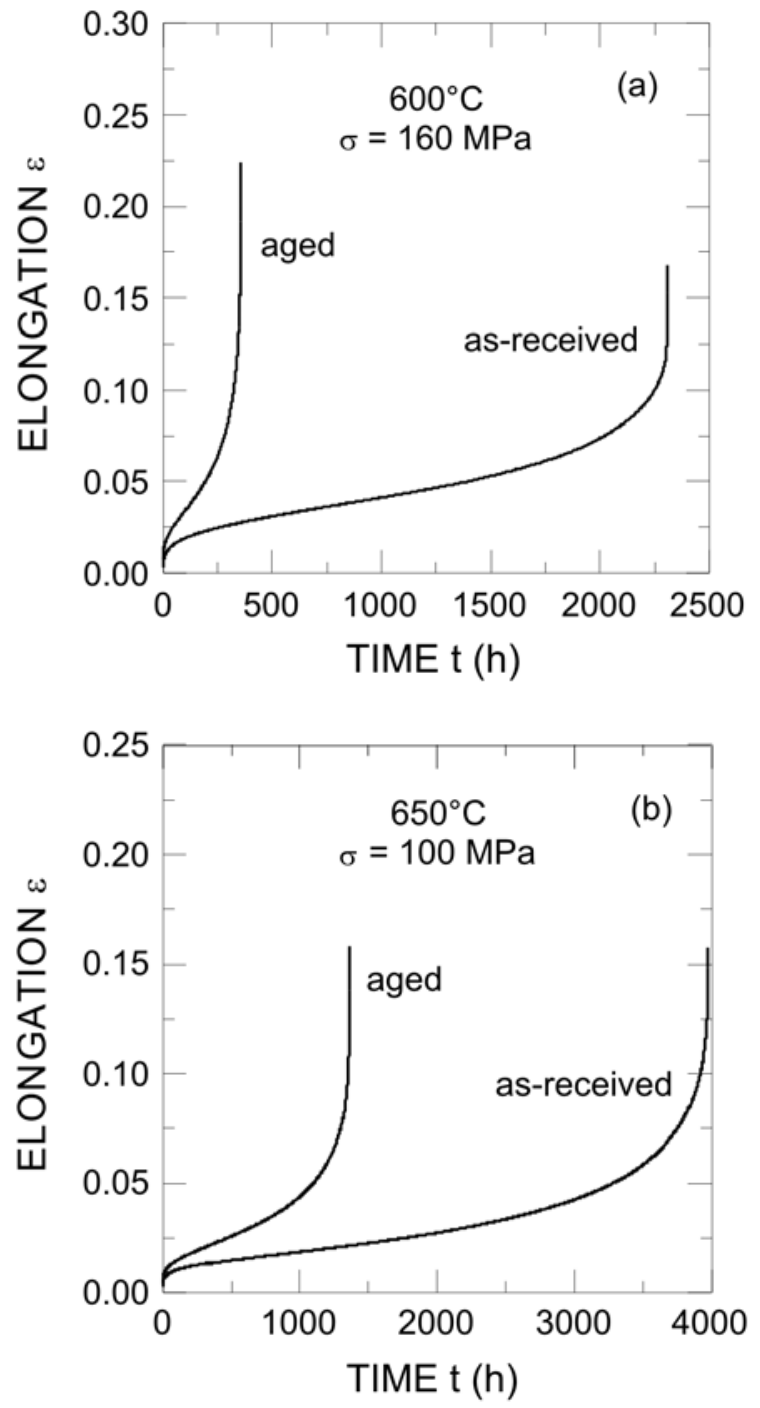

Fig. 2. Standard creep curves of strain vs. time for P92 steel in as-received (AR) and aged (IA) states at (a) $600{ }^{\circ} \mathrm{C}$, $160 \mathrm{MPa}$, and (b) $650^{\circ} \mathrm{C}, 100 \mathrm{MPa}$.

creep rates for the as-received state are somewhat lower than those of the aged state. Further, the apparent stress exponent of the minimum creep rate $n=\left(\partial \ln \dot{\varepsilon}_{\mathrm{m}} / \partial \ln \sigma\right)_{\mathrm{T}}[27]$ increases with increasing stress. Similarly, the stress dependences of the times to fracture $t_{\mathrm{f}}$ are illustrated by Fig. 1b showing that at the same applied stresses the times to fracture $t_{\mathrm{f}}$ of the as-received state are longer than those for the aged state. Again, the values of the stress exponent of the time to fracture $m=\left(\partial \ln t_{\mathrm{f}} / \partial \ln \sigma\right)_{\mathrm{T}}[27]$ are not constant in the experimental range of applied stress $\sigma$. Finally, Fig. 1c shows the stress dependence of strain to fracture $\varepsilon_{\mathrm{f}}$. From similar values of the stress exponent of the minimum creep rate and the time to fracture (the slopes in Figs. 1a and 1b), it is assumed that creep deformation and fracture are controlled by the same mechanism(s). 

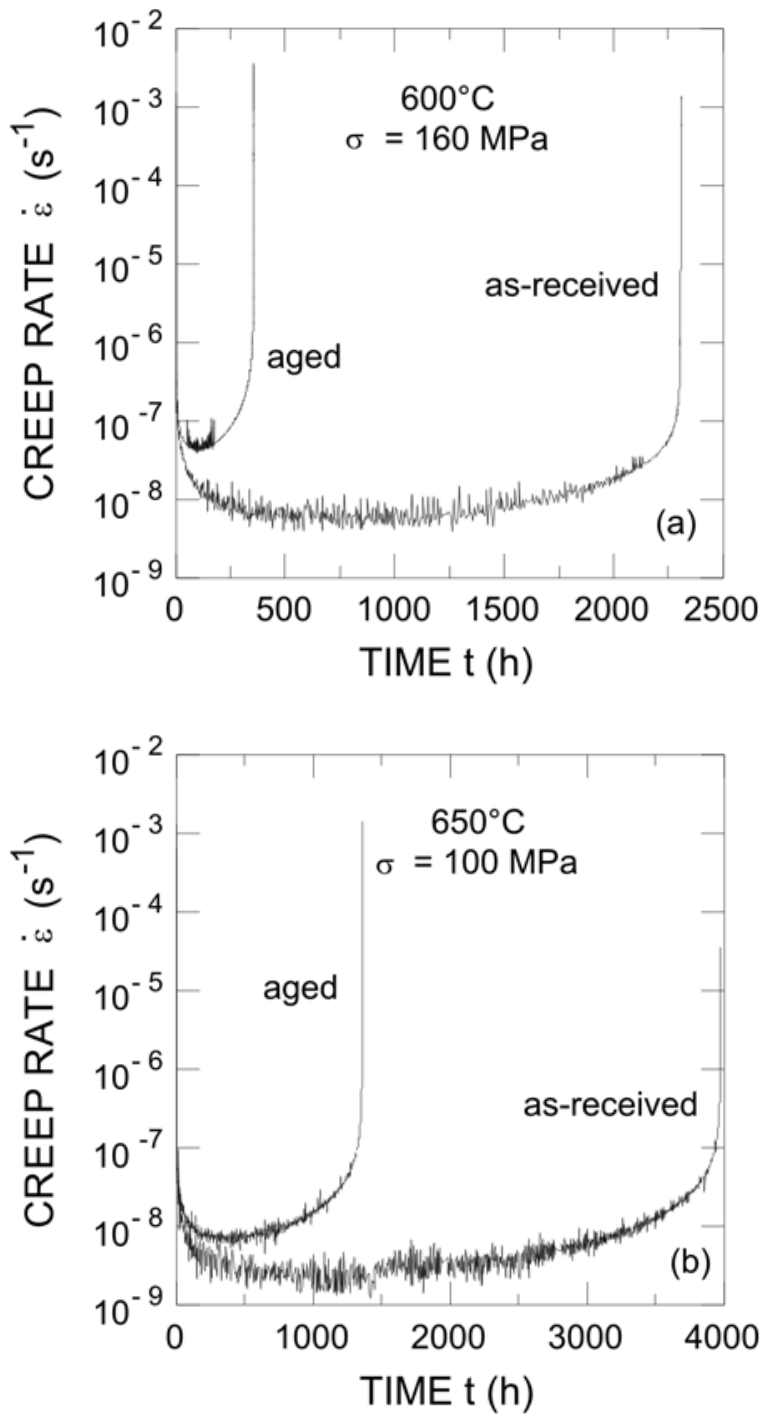

Fig. 3. Replotted standard creep curves shown in Fig. 2 into $\dot{\varepsilon}$ vs. $t$ : (a) $600^{\circ} \mathrm{C}, 160 \mathrm{MPa}$, (b) $650{ }^{\circ} \mathrm{C}, 100 \mathrm{MPa}$.

\subsection{Creep curves and measurement of the minimum creep rate $\dot{\varepsilon}_{\mathrm{m}}$}

Representative standard creep curves of the as-received state and the aged state at 600 and $650{ }^{\circ} \mathrm{C}$ are shown in Fig. 2. The shapes of the creep curves for the as-received state differ considerably from the tests conducted in the aged state. The as-received state exhibits markedly longer creep life than the aged state under the same loading conditions. Independent of the state of material, the creep elongation is characterised by a small instantaneous loading strain followed by a transient (primary) creep, and a rapid increase in the creep rate during the tertiary creep rate. The accumulation of creep strain in the tertiary creep is observed to be large compared to that in the transient creep regime, and rapid creep strain accumulation is
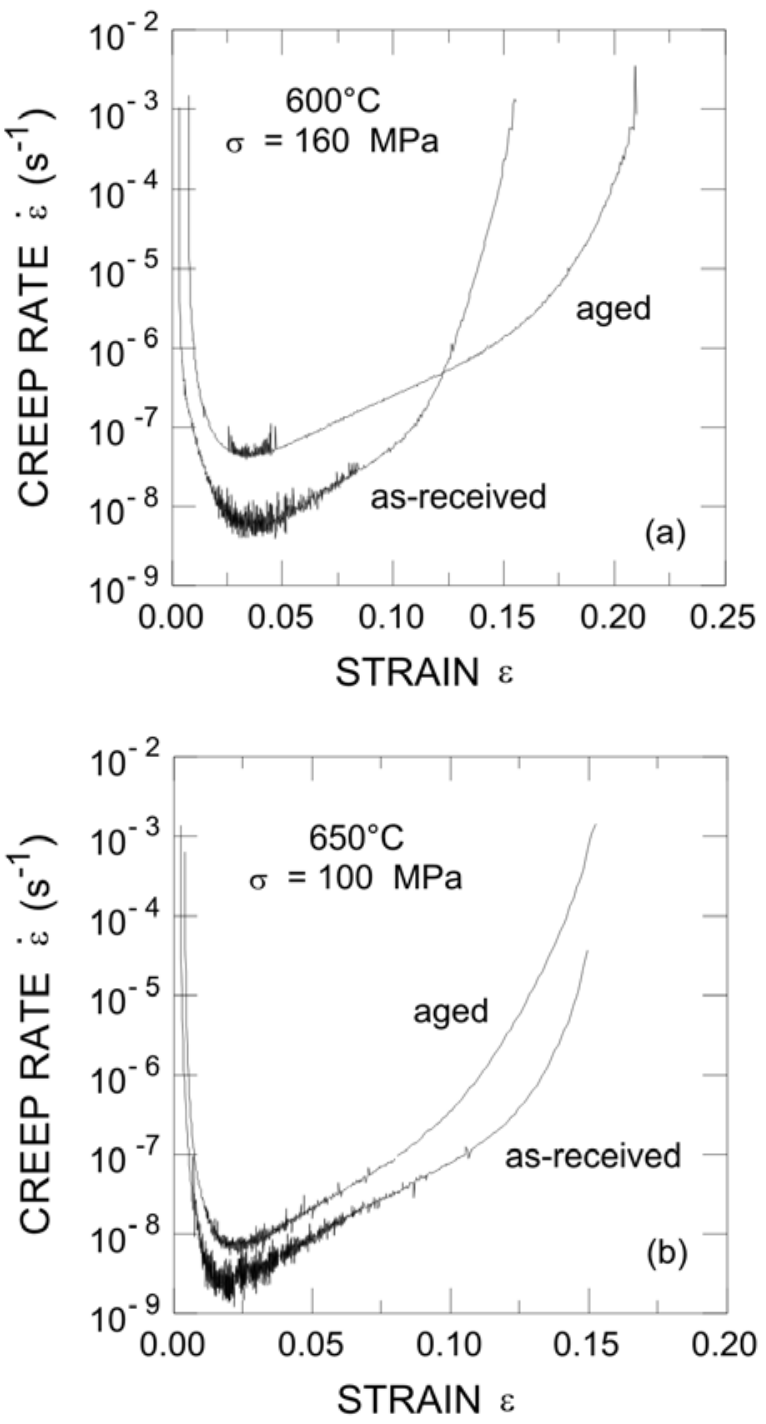

Fig. 4. Replotted standard creep curves shown in Fig. 2 into $\dot{\varepsilon}$ vs. $\varepsilon$ : (a) $600{ }^{\circ} \mathrm{C}, 160 \mathrm{MPa}$, (b) $650{ }^{\circ} \mathrm{C}, 100 \mathrm{MPa}$.

observed in the tertiary creep just before final fracture.

It is important to note that the standard creep curves shown in Fig. 2 do not clearly indicate the individual stages of creep, especially as concerns the occurrence of the steady-state creep region and measurement of the minimum creep rate $\dot{\varepsilon}_{\mathrm{m}}$. However, these standard $\varepsilon$ vs. $t$ curves can be easily replotted in the form of the instantaneous strain rate $\dot{\varepsilon}$ versus time $t$, eventually $\dot{\varepsilon}$ versus strain $\varepsilon$, as shown in Figs. 3 and 4 , respectively. It is clear that neither curve exhibits a well-defined steady-state. In fact, this stage is reduced to an inflection point of the $\dot{\varepsilon}$ vs. $t$ curve. The replotted curves show that tertiary creep covers the prevailing duration of creep exposure. The minimum creep rate $\dot{\varepsilon}_{\mathrm{m}}$ is reached just at the time to onset of tertiary creep $t_{\mathrm{ot}}$. 

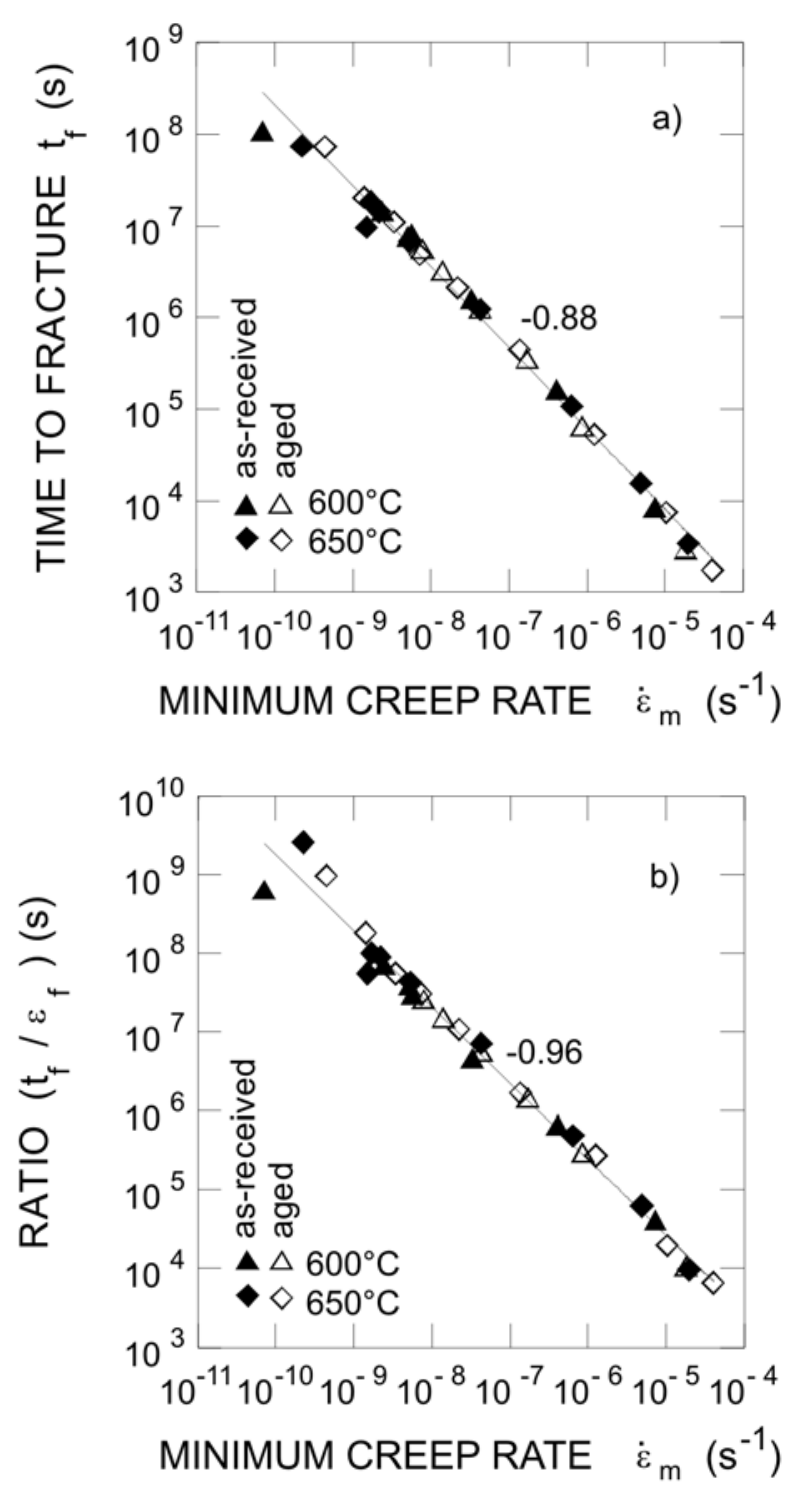

Fig. 5. Double logarithmic plots of (a) Monkman-Grant, (b) modified Monkman-Grant relationships.

\subsection{Creep fracture data}

It follows from Eq. (1) that the minimum creep rate $\dot{\varepsilon}_{\mathrm{m}}$ can be linked to the time to fracture $t_{\mathrm{f}}$ using the Monkman-Grant relationship [18]. A double logarithmic representation of this relationship applied to the experimental results is shown in Fig. 5a. Similar to Fig. 5a, the modified Monkman-Grant relationship (Eq. (2)) can be plotted as the slope of $\log \left(t_{\mathrm{f}} / \varepsilon_{\mathrm{f}}\right)$ vs. $\log \dot{\varepsilon}_{\mathrm{m}}-$ Fig. 5b. It is noteworthy that nearly all the experimental results can be fitted with very good confidence by a single set of parameters, and $t_{\mathrm{f}}$ is approximately inversely proportional to $\dot{\varepsilon}_{\mathrm{m}}$. The linear dependence of the time to fracture on the minimum creep rate that is observed in Fig. 5a indicates that fracture strain $\varepsilon_{\mathrm{f}}$ is defor-
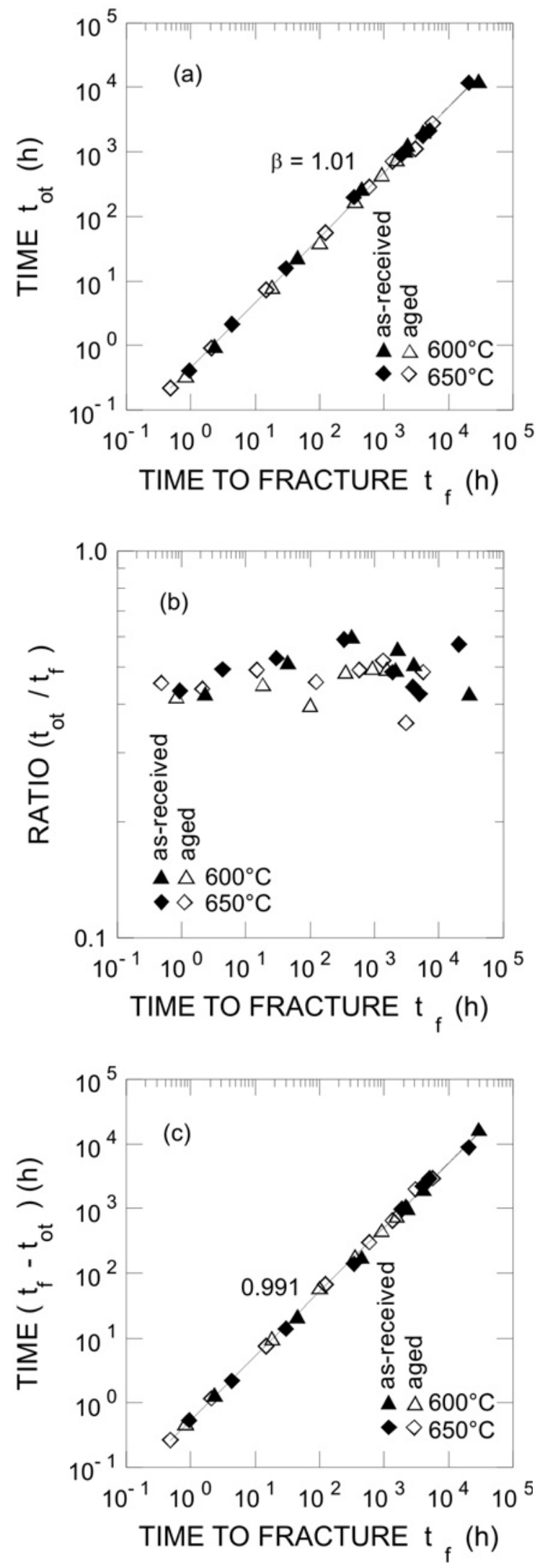

Fig. 6. Double logarithmic plots of (a) time to onset of tertiary creep $t_{\mathrm{ot}}$ vs. time to fracture $t_{\mathrm{f}}$, (b) ratio $\left(t_{\mathrm{ot}} / t_{\mathrm{f}}\right.$ vs. $\left.t_{\mathrm{f}}\right)$, and (c) time $\left(t_{\mathrm{f}}-t_{\mathrm{ot}}\right)$ vs. $t_{\mathrm{f}}$. 


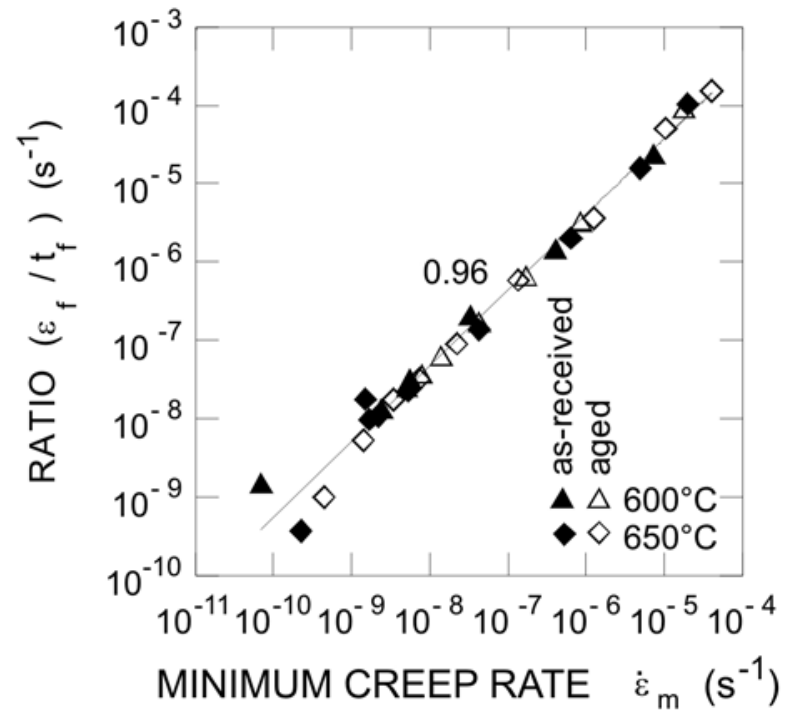

Fig. 7. Double logarithmic plot of the ratio $\left(\varepsilon_{\mathrm{f}} / t_{\mathrm{f}}\right)$ on the minimum creep rate $\dot{\varepsilon}_{\mathrm{m}}$.

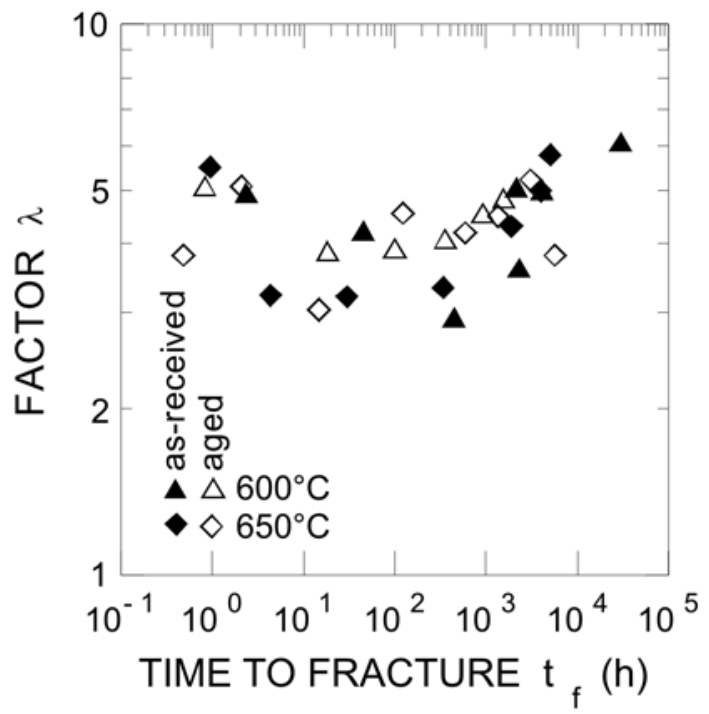

Fig. 8. Double logarithmic plot of the calculated values of the factor $\lambda$ on the time to fracture $t_{\mathrm{f}}$.

mation controlled under the testing conditions chosen here.

Most creep curves obtained here consist of two distinct regimes: primary and tertiary, and a minimum creep rate regime in the transition (Fig. 3). The time to onset of tertiary creep $t_{\mathrm{ot}}$ has been determined from the creep curve as the time at which the creep rate exhibits a minimum; beyond this, the accelerated creep rate leads to tertiary creep. When $t_{\text {ot }}$ data are plotted against $t_{\mathrm{f}}$ on a double logarithmic scale, all data fall on a straight line whose slope is the value $\sim 1$, as shown in Fig. 6a. The time to onset of tertiary creep
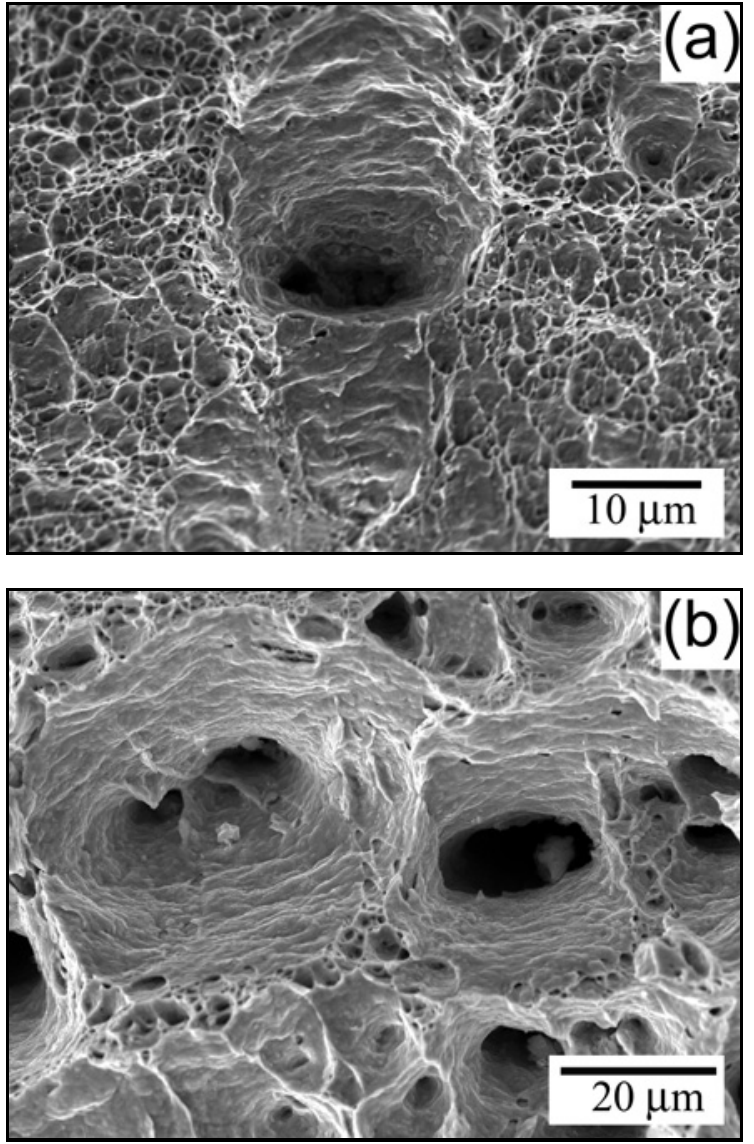

Fig. 9. SEM fractographs showing a transgranular fracture in the specimen crept at $650^{\circ} \mathrm{C}$ and $175 \mathrm{MPa}$. Large plastic deformation is shown by the formation of slip lines on the dimples (Fig. 9b).

$t_{\text {ot }}$ is related to the time to fracture $t_{\mathrm{f}}$ as

$$
t_{\mathrm{ot}}=\xi t_{\mathrm{f}}
$$

where $\xi$ is a constant practically independent of temperature. The value of $\xi$ was about 0.4 (Fig. $6 \mathrm{~b}$ ), which demonstrates that this steel spent a majority of creep exposure in the tertiary regime of creep deformation, in agreement with Fig. 6c. Thus, using Eq. (4), the creep life of the steel P92 can be predicted by evaluating the time to onset of tertiary creep $t_{\text {ot }}$ after carrying out the creep test up to the initial stage of tertiary creep.

From the definition of the creep damage tolerance factor $\lambda$ (Eq. (3)), it follows that $\varepsilon_{\mathrm{f}} / t_{\mathrm{f}}=\lambda \dot{\varepsilon}_{\mathrm{m}}$ and $\lambda$ can be determined using the double logarithmic plot of $\varepsilon_{\mathrm{f}} / t_{\mathrm{f}}$ vs. $\dot{\varepsilon}_{\mathrm{m}}$ (Fig. 7) as the intercept at $\dot{\varepsilon}_{\mathrm{m}}=1$. However, it can be expected that the factor $\lambda$ is not constant, and the steel could exhibit different values of $\lambda$ for low and high-stress regimes. Therefore, another possibility of how to determine the factor $\lambda$ directly is to calculate its value from the experimental data 

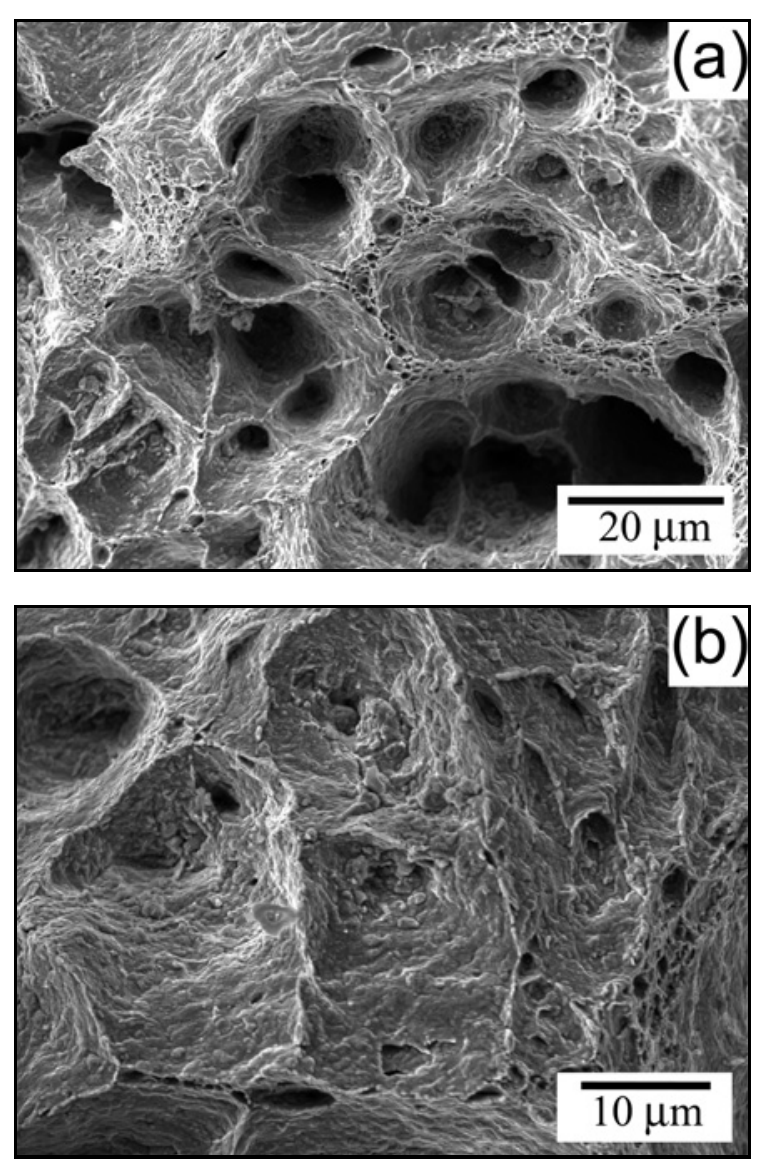

Fig. 10. SEM fractographs showing a mixture of transgranular and intergranular fracture (creep at $600^{\circ} \mathrm{C}$ and $140 \mathrm{MPa}$ ). Plastic deformation is involved in interlinking of neighbouring cavities.

presented in Fig. 1 using Eq. (3). The plot of the calculated variable values of $\lambda$ vs. the time to fracture in this way is shown in Fig. 8, demonstrating the dependence of $\lambda$ on loading conditions $\left(t_{\mathrm{f}}=t_{\mathrm{f}}(\sigma, T)\right)$.

\subsection{Creep damage and fractography}

Fracture surface examination by SEM of creep fractured specimens at various applied stresses, and two test temperatures are shown in Figs. 9-11. The SEM observations clearly indicate that creep fracture of specimens with very short-term exposures at high applied stresses is dominated by the plastic straining of the matrix independently of their microstructural state. Creep fracture is due to a local loss of stability of plastic deformation (i.e. damage by a loss of the external section due to extensive necking). The mechanisms are similar to those occurring in the tensile tests at high temperatures. Typical transgranular ductile fracture characterised by dimples can be seen in Fig. 9. With increasing creep exposure, the fracture is characterised by a prevalent combination of trans-
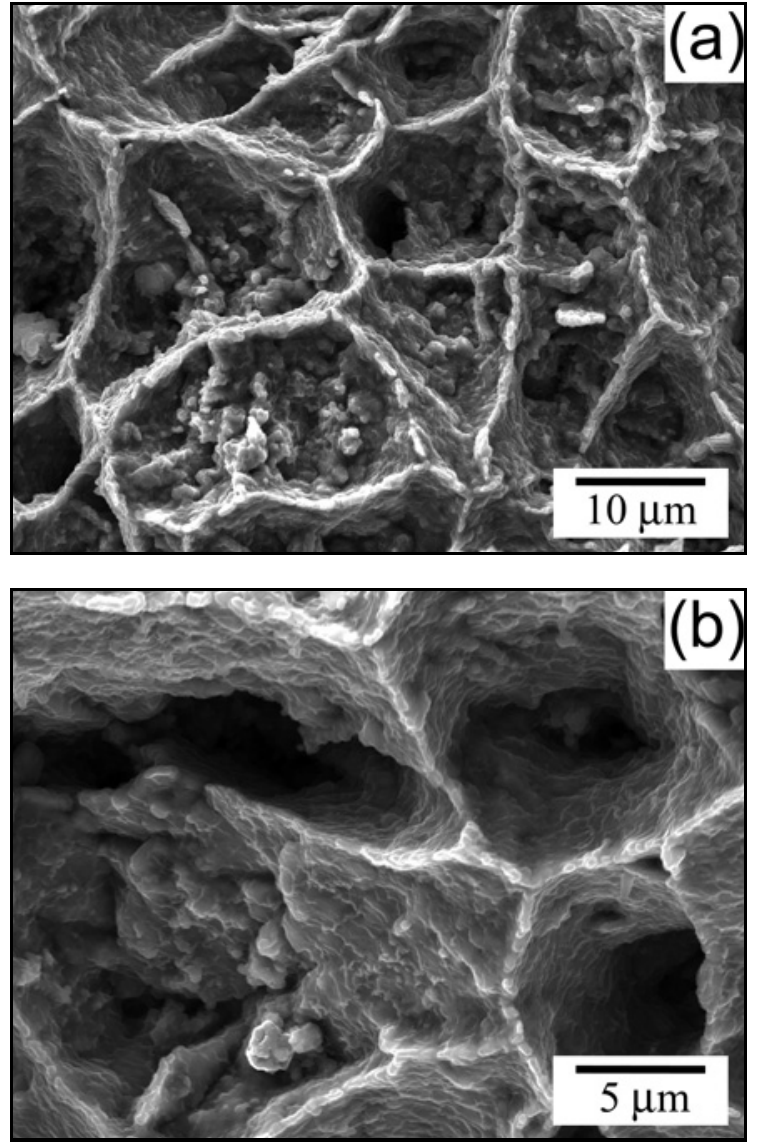

Fig. 11. SEM fractographs showing extensive cavitation (creep at $650^{\circ} \mathrm{C}$ and $85 \mathrm{MPa}$ ). Note that interlinkage of cavities is due to cavity growth (Fig. 11b).

granular and intergranular modes as a result of a mixture of transgranular dimples and intergranular damage with changes in the size and density of dimples, and extensive coalescence of cavitation damage, depending on the applied stress and testing temperature (Fig. 10). However, for long-term creep exposures, we can expect dominance of microstructural degradation due to the coarsening and/or disappearance of secondary phase precipitates and rearrangement of dislocation substructure. Nevertheless, in this case, the morphology of the fracture surface is not thoroughly clear due to oxidation (Fig. 11).

Typical creep damage occurs by the loss of internal cross section due to intensive intergranular cavitation and changes in the microstructure [28]. Creep cavities were observed in different shapes and numbers in the crept specimens at both testing temperatures and microstructural conditions. In general, the mechanisms of cavity nucleation and growth are linked to local creep strain, with the cavity growth considered to be constrained by deformation of the local matrix [29-31]. However, their occurrence was preferentially 

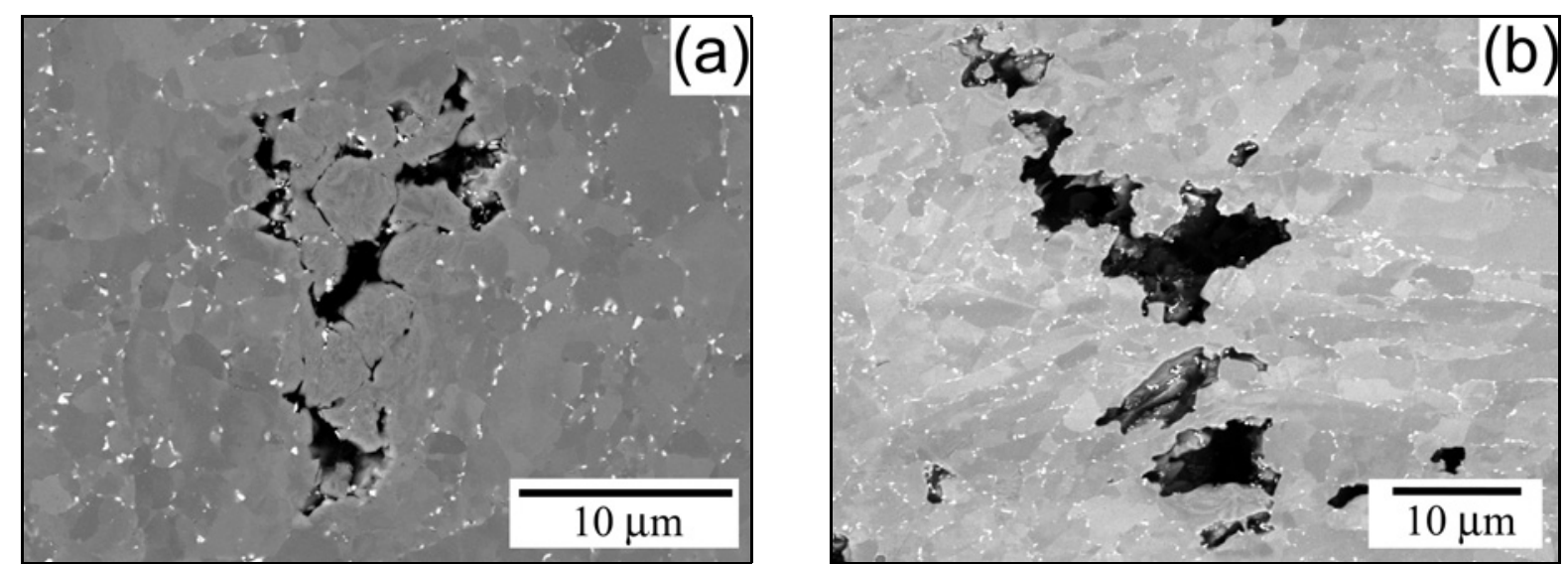

Fig. 12. Cavitation in specimen crept at $600^{\circ} \mathrm{C}$ and $140 \mathrm{MPa}$ : (a) cavity formation at the triple points (wedge cracks and their coalescence), (b) sharp-edged shape of cavities and their aggregates of coalescence.
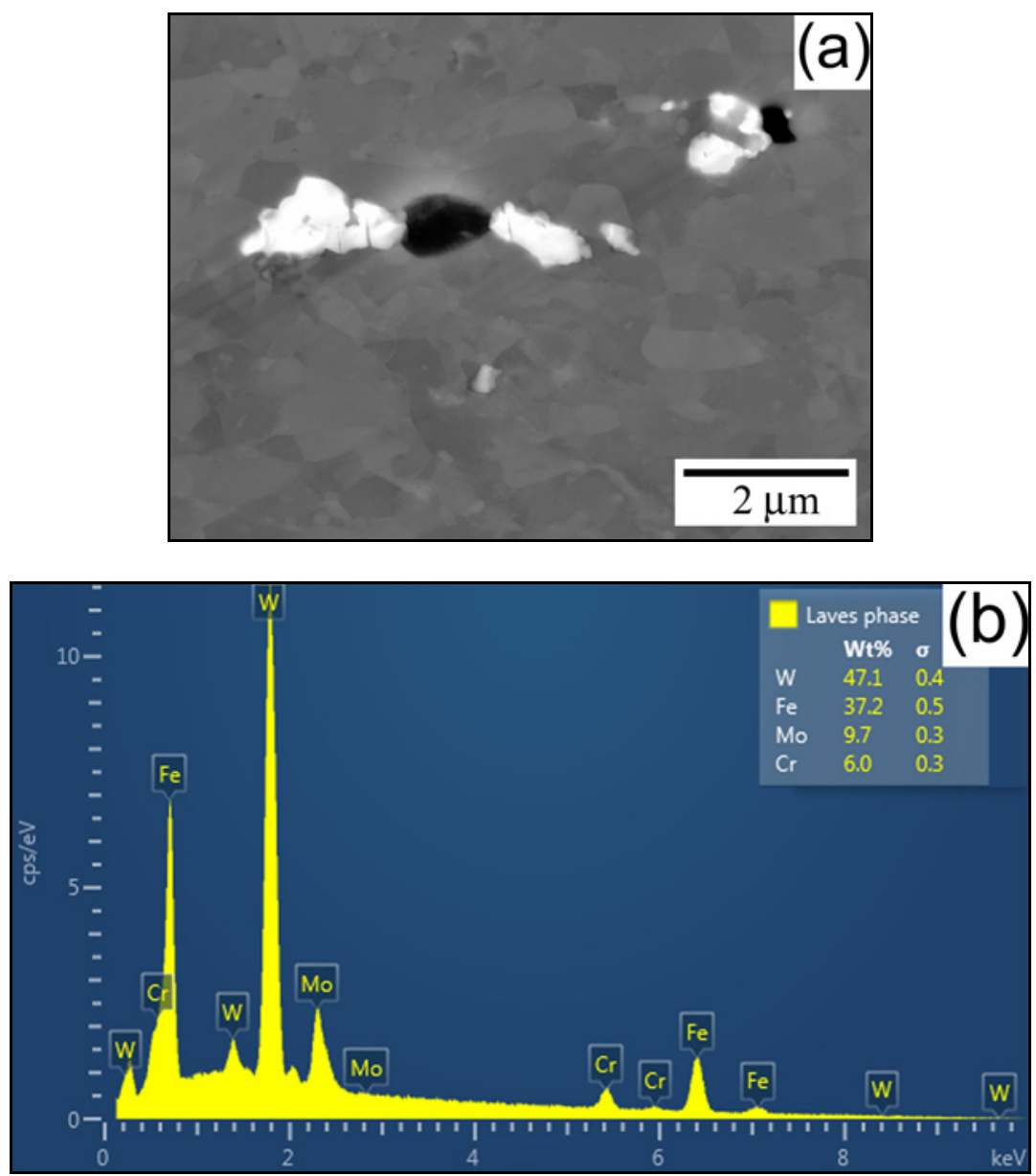

Fig. 13. (a) Round-shaped cavity between two particles of Laves phase (creep at $650^{\circ} \mathrm{C}$ and $80 \mathrm{MPa}$ ), (b) EDX spectra of Laves phase precipitates.

observed in the medium and low-stress regimes (up to $140 \mathrm{MPa}$ at $600^{\circ} \mathrm{C}$ and $100 \mathrm{MPa}$ at $\left.650^{\circ} \mathrm{C}\right)$. In the medium stress regime, cavities are frequently formed at the triple grain junction, at which a high density of Laves phase particles is present (labelled as wedge-cracks: [27, 31, 32] - Fig. 12a). Cavities can grow and coalesce most probably by power-law creep [22, 27] of the surrounding grains, as shown in Fig. $12 \mathrm{~b}$. Furthermore, the cavities exhibit a sharp-edged shape (Fig. 12b) that does not provide evidence about cavity growth by coupled diffusion and power-law creep $[33,34]$. Such a coupled mechanism seems to be more 

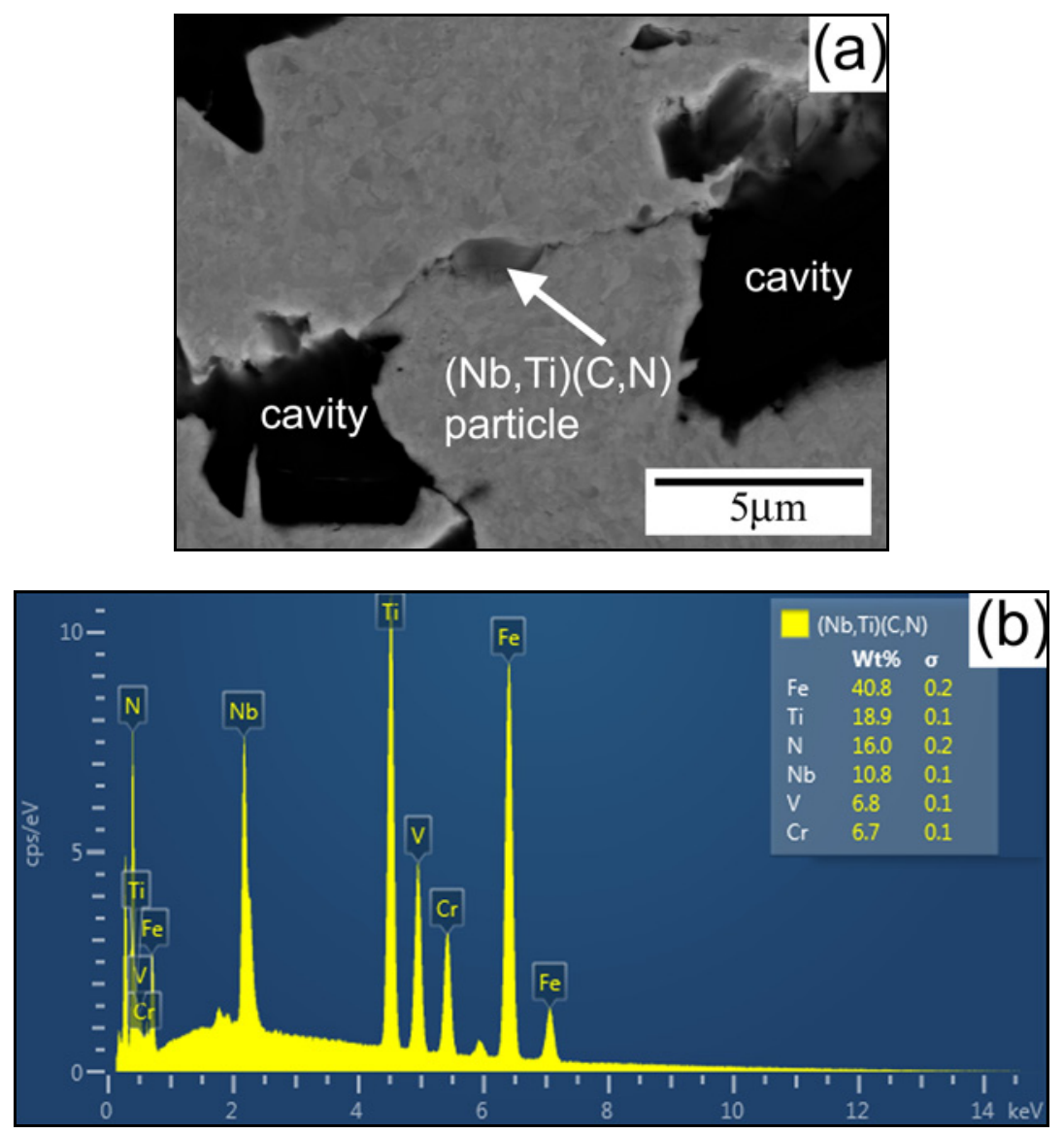

Fig. 14. Typical EDAX analysis of a coarse $(\mathrm{Nb}, \mathrm{Ti})(\mathrm{C}, \mathrm{N})$ particle located between two coalescences of creep cavities in specimen crept at $650{ }^{\circ} \mathrm{C}$ and $110 \mathrm{MPa}$ (a) SEM micrograph and (b) EDX spectra of the precipitate.

feasible in the low-stress regime, where cavities have a more round shape (Fig. 13a). However, in both stress regimes, the cavities are usually attached to coarse particles of the Laves phase (Fig. 13b), suggesting that the precipitation and coarsening of the Laves phase are responsible for the nucleation of cavities and the formation of the intergranular fracture. Cippola et al. [35] observed that intergranular brittle fracture occurred at the onset of coarsening Laves phase particles. Furthermore, Lee et al. [9] reported that the coarsening of Laves phase particles beyond a critical size triggered cavity formation and consequent brittle intergranular fracture. No interrelationship between cavities and sporadically scarce coarse $(\mathrm{Nb}, \mathrm{Ti})(\mathrm{C}, \mathrm{N})$ particles was found (Fig. 14). In contrast, $\mathrm{Gu}$ et al. [36] identified several particles of $\mathrm{BN}, \mathrm{MnS}$ and $\mathrm{Al}_{2} \mathrm{O}_{3}$ associated with cavities in crept P92 steel.

\section{Discussion}

Since it is not possible to measure the creep life directly under the service conditions due to long times needed, various methods are used to predict creep behaviour from accelerated tests. It is very difficult to separate individual effects of various acting processes, so the complete physical description based on fundamental laws has not been available until now [37]. Phenomenological and empirical approaches are then used for predictive modelling of the creep process. Some models try to predict the whole creep curve, while others deal with some parameters only, of which the time to fracture $t_{\mathrm{f}}$ is the most important one.

In this work, the last approach was demonstrated by empirical relationships based on the MonkmanGrant rule and its modification. The practical advantage of the Monkman-Grant relationship is that the minimum creep rate $\dot{\varepsilon}_{\mathrm{m}}$ can be measured early in the creep life. Provided that the value of $C_{\mathrm{MG}}$ has been determined in relatively short-term tests, the time to fracture in long-term tests can be predicted from $t_{\mathrm{f}}=C_{\mathrm{MG}} / \dot{\varepsilon}_{\mathrm{m}}$ once the minimum creep rate has been established. This means a substantial reduction of testing time. Thus, simple empirical models could be useful tools for engineering practice, but their limitations and reliability must be realised, mainly when applied on new materials.

Unfortunately, we are some distance from fully understanding the role of the Laves phase in the creep damage evolution of P92 steel. From the creep 
strengthening point of view, the precipitation of the Laves phase has two aspects. First, high amounts of $\mathrm{W}$ and Mo are incorporated in this phase, causing the depletion of these elements from the solid solution, and thus a reduction in their contribution to the overall creep resistance. However, Hald [3] concluded that solid solution strengthening from $\mathrm{W}$ and Mo has no significant effect on the long-term microstructural stability of $9-12 \%$ Cr steels. Secondly, the Laves phase coarsens faster than all the other phases present, and some of its particles reach a size of few micrometres. Therefore, the Laves phase could lead to higher precipitation strengthening only during the initial very short precipitation phase, when the beginning of the precipitation of the fine Laves phase might increase the creep resistance. Hence, the precipitation, growth and coarsening of the Laves phase can be accounted for as a degradation mechanism of the microstructure.

It is generally accepted that creep cavities are nucleated in $9-12 \% \mathrm{Cr}$ steels at coarse and hard precipitates of the Laves phase along grain boundaries $[9,15$, 38 , and are considered to be a cause of low ductility at low stresses or in long-term exposures. Figure 13 shows creep cavities located at the Laves phase particle. Thus, the decohesion between the metallic matrix and the large Laves phase precipitates could be the main reason for premature fracture, which occurs at a low value of the fracture strain. With increasing stress, the fracture is characterised by the appearance of large dimples and rather a large creep deformation, which is evidenced by the formation of slip lines on the dimples (Fig. 9b).

Finally, besides fractographic investigations, the creep damage tolerance factor $\lambda$ has been used to assess the creep fracture mode whose value for structural materials ranges from 1-20 [22]. Thus, it is interesting to correlate the evaluated values of $\lambda$ with the results of fractographic investigations and to discuss this aspect. According to Ashby and Dyson [22], for $\lambda=1$ materials exhibit low creep fracture strain and brittle fracture mode without any significant plastic deformation. For $\lambda$ in the range of 1.5-2.5, they suggested that damage is due to the cavity growth resulting from the combined effect of power-law and diffusion creep. Larger values of $\lambda$ indicate that the material can withstand strain concentration without local cracking; the fracture is ductile, and the dominant damage mechanism is necking [22]. The creep damage tolerance factor $\lambda$ determined experimentally has been reported mostly for $9 \mathrm{Cr}-1 \mathrm{Mo}$ steel. Phaniraj et al. [39] and Choudhary [24] used the constant load creep test data obtained on $9 \mathrm{Cr}-1 \mathrm{Mo}$ ferritic steel [40, 41] for their analysis, and reported values of $\lambda=10$ and 5 for low- and high-stress regimes, respectively. Choudhary and Samuel [40] found that modified 9Cr1Mo steel (P91) exhibited a constant value of $\lambda=5$

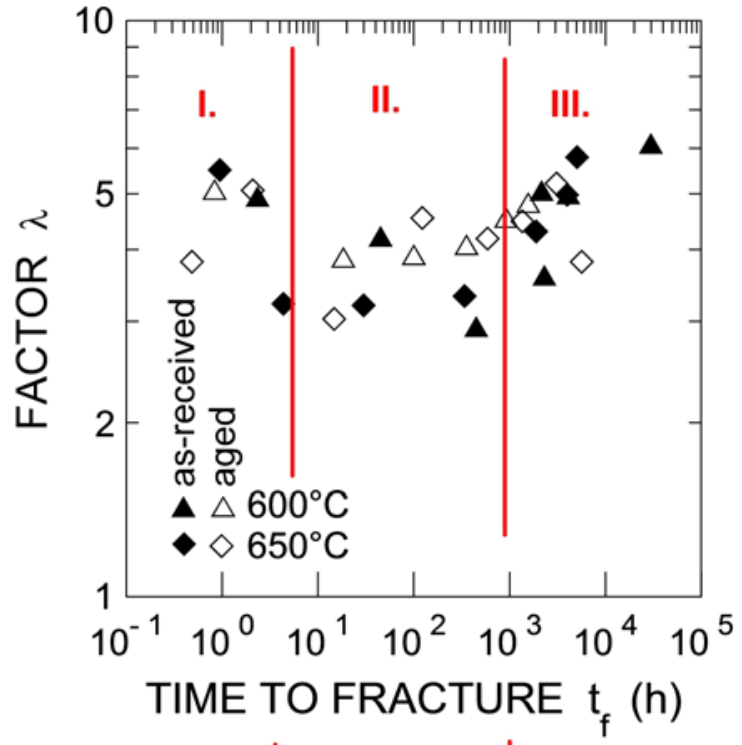

\begin{tabular}{|c|c|c|}
\hline $\begin{array}{c}\text { I. } \\
\text { loss of } \\
\text { external } \\
\text { section } \\
\text { (necking) }\end{array}$ & $\begin{array}{c}\text { II. } \\
\text { loss of } \\
\text { internal } \\
\text { section } \\
\text { (cavitation) }\end{array}$ & $\begin{array}{c}\text { III. } \\
\text { microstructure } \\
\text { degradation } \\
\text { (substructure } \\
\text { acceleration } \\
\text { of creep) }\end{array}$ \\
\hline
\end{tabular}

Fig. 15. Three individual sectors of the parameter $\lambda$ indicating the relevant creep damage mode.

for creep at 550,575 and $600{ }^{\circ} \mathrm{C}$ and for stresses ranging from 125-275 MPa. Shrestha et al. [25] reported the values of $\lambda$ between 4-5 for P91 steel crept in the temperature range of $600-700^{\circ} \mathrm{C}$ and at stresses of 35-350 MPa. Very recently, Sakthivel et al. [14] determined the value of $\lambda=6$ for P92 steel creep tested at 600,650 and $700^{\circ} \mathrm{C}$ over a stress range of $80-220 \mathrm{MPa}$. These differences in the values of $\lambda$ can be assumed to correspond to the variety of the creep damage and fracture mode.

Actually, our value of the creep damage tolerance factor $\lambda$ is not constant and varies from 3-6 depending on creep loading conditions. To explain this range of $\lambda$, Fig. 8 can be redrawn (Fig. 15), indicating three individual sectors of the parameter $\lambda$. Sector I is relevant to damage by loss of an external section of the specimen (necking); intergranular cavitation does not play any role. Creep fracture is transgranular dimple ductile fracture. In Sector II, necking is coupled with a loss of the internal section due to cavitation. It can be expected that in this sector, cavitation is the result of creep flow of the grains or grain boundary sliding $[27,31,37]$. The most frequently observed form of intergranular damage - wedge cracks - was nucleated at triple grain junctions [27, 42], and the kinetics of cavity growth and coalescence is considered to be determined by grain boundary sliding [28], 
and power-law creep [31]. Nevertheless, at a relatively high level of applied stress in Sector II, microcracks at triple grain junctions and/or grain boundary particles may be nucleated athermally. The typical creep fracture in Sector II was a mixture of transgranular and intergranular modes. However, lower values of $\lambda$ indicate that damage may coalesce to form a single dominant crack (Fig. 12b). A complex morphology of creep fracture was observed in Section III. However, as was mentioned in Section 3.3, microstructural degradation like coarsening of precipitates and subgrains, and a decrease in dislocation density, are the dominant creep damage mechanisms, with limited contributions from necking and cavitation, resulting from the combined effect of the power-law and diffusion creep.

\section{Conclusions}

Creep damage and fracture processes in advanced tungsten modified 9\% Cr ferritic steel (ASTM Grade P92) were studied at temperatures of 600 and $650{ }^{\circ} \mathrm{C}$ and in the stress range of $75-250 \mathrm{MPa}$. From similar values of the stress exponents of the minimum creep rate $n$ and the time to fracture $m$, it is assumed that the creep deformation and fracture are controlled by the same mechanisms. The analyses of creep data indicate that creep behaviour of the steel under investigation obeys both Monkman-Grant and modified Monkman-Grant empirical formulas and provides high values of creep damage factor $\lambda$. It was demonstrated that the creep life of the P92 steel could be predicted by measuring the time to onset of tertiary creep $t_{\text {ot }}$ after carrying out the creep test up to the initial stage of tertiary creep. Laves phase particles, which coarsened during creep exposure, served as preferred sites for creep cavity nucleation. The fractography of creep-ruptured specimens revealed dominant dimpled transgranular fracture at the highest stresses and a mixture of transgranular and intergranular fracture modes at medium- and low-stress regions.

\section{Acknowledgements}

We acknowledge financial support for this work provided by the Czech Science Foundation under the Project no. 16-09518S. Some experiments were realised using research infrastructure IPMINFRA supported by the Project LM2015069 financed by the Ministry of Education, Youth and Sports of the Czech Republic.

\section{References}

[1] Mayer, K. H., Masuyama, F.: Creep Resistant Steels. Eds.: Abe, F., Kern. T. U., Viswanathan, R. Cambridge, Woodhead Publishing Ltd. 2008.

[2] Abe, F.: Materials for Ultra-Supercritical and Advanced Ultra-Supercritical Power Plants. Ed.: Di Gianfrancesco, A. Cambridge, Woodhead Publ. Ltd. 2016.

[3] Hald, J.: Int J Press Ves Pip, 85, 2008, p. 30. doi:10.1016/j.ipvp.2007.06.010

[4] Sklenička, V., Kuchařová, K., Svoboda, M., Kloc, L., Buršík, J., Kroupa, A.: Mater Charact, 51, 2003, p. 35. doi:10.1016/i.matchar.2003.09.012

[5] Hasegawa, Y.: Coal Power Plant Materials and Life Assessment - Developments and Applications. Ed.: Shibli, A. Cambridge, Woodhead Publishing in Materials Ltd. 2014.

[6] Klueh, R. L.: Int Mater Rev, 50, 2005, p. 287. doi:10.1179/174328005X41140

[7] Naoi, H., Ohgami, M., Araki, S., Ogawa, T., Yasuda, H., Masumoto, H., Fujita, T.: Nippon Steel Tech Rep, 50, 1991, p. 7.

[8] Barbadikar, D. R., Deshmukh, G. S., Maddi, L., Laha, K., Parameswaran, P., Ballal, A. R., Peshwe, D. R., Paretkar, R. K., Nandagopal, M., Mathew, M. D.: Int J Press Ves Pip, 132-133, 2015, p. 97. doi:10.1016/i.ijpv.2015.07.001

[9] Lee, J. S., Armaki, H. G., Maruyama, K., Muraki, T., Asahi, H.: Mater Sci Eng A, 428, 2006, p. 270. doi:10.1016/j.msea.2006.05.010

[10] Kim, B., Jeong, C., Lim, B.: Mater Sci Eng A, 483484, 2008, p. 544. doi:10.1016/i.msea.2006.12.151

[11] Wang, X., Shi, Z., Pan, Q. G., Wu, H. L.: Trans Nonferrous Met Soc China, 19, 2009, p. s772. doi:10.1016/S1003-6326(10)60149-5

[12] Wang, X., Pan, Q. G., Liu, Z. J., Zeng, H. Q., Tao, Y. S.: Eng. Fail. Anal., 18, 2011, p. 186. doi:10.1016/j.engfailanal.2010.08.020

[13] Wang, X., Pan, O. G., Ren, Y. Y., Shang, W., Zeng, H. Q., Liu, H.: Mater Sci Eng A, 552, 2012, p. 493. doi:10.1016/i.msea.2012.05.076

[14] Sakthivel, T., Panneer Selvi, S., Laha, K.: Mater Sci Eng A, 640, 2015, p. 61. doi:10.1016/j.msea.2015.05.068

[15] Sklenička, V., Kuchařová, K., Král, P., Kvapilová, M., Svobodová, M., Ćmakal, J.: Mater Sci Eng A, 644, 2015, p. 297. doi:10.1016/j.msea.201507.072

[16] Schüller, H. J., Hagn, L., Woitscheck, A., Kober, A., Christian, H.: In: Proceedings of VGB-Konferenz Werkstoffe und Schweisstechnik im Kraftwerk. VGB, Essen 1974, p. 163. (in German)

[17] Cerjak, H., Mayr, P.: Creep Resistant Steels. Eds.: Abe, F., Kern, T. U., Viswanathan, R. Cambridge, Woodhead Publishing in Materials Ltd. 2008.

[18] Monkman, F. C., Grant, N. J.: Proc ASTM, 56, 1956, p. 593.

[19] Dobeš, F., Milička, K.: Met Sci, 10, 1976, p. 382. doi:10.1080/03063453.1976.11683560

[20] Goodall, I. N., Cockcroft, R. D. H., Chubb, E. J.: Int J Mech Sci, 17, 1975, p. 351. doi:10.1016/0020-7403(75)90027-2

[21] Leckie, F. A., Hayhurst, D. R.: Acta Metall, 25, 1977, p. 1059. doi:10.1016/0001-6160(77)90135-3 
[22] Ashby, M. F., Dyson, B. F.: Advances in Fracture Research. Volume 1. Eds.: Valuri, S. R., Taplin, D. M. R., Rama Rao, P., Knott, J. F., Dubey, R. Oxford, Pergamon Press 1984.

[23] Dyson, B. F., Gibbons, T. B.: Acta Mater, 36, 1987, p. 2355. doi:10.1016/0001-6160(87)90083-6

[24] Choudhary, B. K.: Mater Sci Eng A, 585, 2013, p. 1. doi:10.1016/j.msea.2013.07.026

[25] Shrestha, T., Basirat, M., Charit, I., Potirniche, G. P., Rink, K. K.: Mater Sci Eng A, 565, 2013, p. 382. doi:10.1016/i.msea.2012.12.031

[26] Latha, S., Mathew, M. D., Parameswaran, P., Laha, K., Panneer Selvi, S., Mannan, S. L.: Procedia Eng., 55, 2013, p. 58. doi:10.1016/i.proeng.2013.03.219

[27] Čadek, J.: Creep in Metallic Materials. Amsterdam, Elsevier 1988.

[28] Sklenička, V.: Modelling and Microstructural Evolution in Creep Resistant Materials. Eds.: Strang, A., McLean, M. Cambridge, University Press 1999.

[29] Dyson, B. F.: Met Sci, 10, 1976, p. 349. doi:10.1179/030634576790431417

[30] Beere, W.: Cavities and Cracks in Creep and Fatigue. Ed.: Gittus, J. London, Applied Science Publishers Ltd. 1981.

[31] Riedel, H.: Fracture at High Temperature. Berlin, Springer Verlag 1986.

[32] Evans, H.: Mechanisms of Creep Fracture. London, Elsevier Appl. Science Publishers 1984.

[33] Svoboda, J., Turek, I., Sklenička, V.: Acta Met Mat, 38, 1990, p. 573. doi:10.1016/0956-7151(90)90211-X
[34] Needleman, A., Rice, J. R.: Acta Metall. 28, 1980, p. 1315. doi:10.1016/0001-6160(80)90001-2

[35] Cippola, L., Di Gianfrancesco, A., Venditti, D., Cumino, G.: In: Proceedings of the ASME Pressure Vessels and Piping Conference 2007. Volume 9. Ed.: Jaske, C. E. New York, ASME, p. 445. ISBN: 978-07918-4287-4.

[36] Gu, Y., West, G. D., Thomson, R. C., Parker, J..: In: Proc. of 7th Conference on Advances in Materials Technology for Fossil Power Plants. Eds.: Gandi, D., Shingledecker, J. Materials Park, ASM International 2013, p. 596. ISBN: 978-1-62708-060-6.

[37] Sklenička, V., Kloc, L.: Power Plant Life Management and Performance Improvement. Ed.: Oakey, J. E. Cambridge, Woodhead Publishing Ltd. 2011.

[38] Fedorova, I., Belzakov, A., Kozlov, P., Skorobogatykh, V., Shenkova, I., Kaibyshev, R.: Mater Sci Eng A, 615, 2014, p. 153. doi:10.1016/i.msea.2014.07.046

[39] Phaniraj, C., Choudhary, B. K., Bhana Sankara Rao, K., Raj, B.: Scripta Mater, 48, 2003, p. 1313. doi:10.1016/S1359-6462(03)00021-6

[40] Choudhary, B. K., Samuel, E. I.: J Nucl Mater, 412, 2011, p. 82. doi:10.1016/i.nucmat.2011.02.024

[41] Choudhary, B. K., Saroja, S., Bhana Sankara Rao, L., Mannan, S. L.: Metall Mater Trans A, 30, 1999, p. 2825. doi:10.1007/s11661-999-0120-y

[42] Yoo, M. H., Trinkaus, H.: Acta Metall, 34, 1986, p. 2381. doi:10.1016/0001-6160(86)90141-0 